Check for updates

Cite this: RSC Adv., 2017, 7, 22510

Received 22nd March 2017 Accepted 16th April 2017

DOI: $10.1039 / \mathrm{c} 7 \mathrm{ra03370b}$

rsc.li/rsc-advances

\title{
Effect of alkali-metal cations on the electrochemical reduction of carbon dioxide to formic acid using boron-doped diamond electrodes
}

\begin{abstract}
Norihito Ikemiya, ${ }^{a}$ Keisuke Natsui, ${ }^{a}$ Kazuya Nakata ${ }^{b}$ and Yasuaki Einaga (D) *ac
The electrochemical reduction of carbon dioxide in aqueous solutions using boron-doped diamond (BDD) electrodes was investigated at ambient pressure and temperature. We discuss the effects of the alkali-metal (AM) cations, $\mathrm{K}^{+}, \mathrm{Na}^{+}, \mathrm{Rb}^{+}$and $\mathrm{Cs}^{+}$, on the faradaic efficiency (FE) for the formation of formic acid. An FE of $71 \%$ was achieved in the case of a $0.075 \mathrm{M} \mathrm{Rb}^{+}$solution neutralized to $\mathrm{pH} 6.2$ by the addition of $\mathrm{HCl}$. In the case of a Cs${ }^{+}$solution neutralized to $\mathrm{pH} 6.2$, the highest FE was obtained with the more dilute concentration of $0.02 \mathrm{M}$. Of the four different solutions examined, the lowest FE was observed for the $\mathrm{Na}^{+}$solution. Moreover, we found that the productivity for the production of formic acid is higher at higher current densities.
\end{abstract}

\section{Introduction}

The large amount of $\mathrm{CO}_{2}$ emissions has become a serious problem from the point of view of global warming. For example, thermal power plants that generate electric power have been discharging large amounts of $\mathrm{CO}_{2}$ into the atmosphere. So, for the past several decades, much attention has been paid to the recycling of $\mathrm{CO}_{2}$ to produce valuable chemicals such as $\mathrm{CO}$, $\mathrm{CH}_{4}$, formic acid, formaldehyde, methanol and products derived from these. ${ }^{1}$

The $\mathrm{CO}_{2}$ molecule is sufficiently thermodynamically stable that $\mathrm{CO}_{2}$ cannot be converted into any other useful substance without activating it. However, it is easy to activate $\mathrm{CO}_{2}$ molecules at ambient pressure and temperature using electrochemical methods. There have been many reports presented on the electrochemical reduction of $\mathrm{CO}_{2}$ using various kinds of metal and semiconductor electrodes. ${ }^{2,3}$ Some noble metal electrodes such as $\mathrm{Pt}, \mathrm{Au}$ and $\mathrm{Cu}$ convert $\mathrm{CO}_{2}$ to $\mathrm{CO}$ or $\mathrm{CH}_{4}$ molecules without the formation of formic acid owing to the different catalytic pathways on these electrode surfaces. ${ }^{4}$ Although Sn electrodes enable us to produce formic acid from $\mathrm{CO}_{2}$ with a very high faradaic efficiency (FE) of $65-90 \%$, this electrode material is unstable and unable to maintain a stable FE for the production of formic acid. ${ }^{5,6}$ Using a methanol-based electrolyte, Mizuno et al. have reported that formic acid could be formed with a high yield of around $70 \%$ using $\mathrm{Pb}$ electrodes at ambient pressure. ${ }^{7}$ Considering the

${ }^{a}$ Department of Chemistry, Keio University, 3-14-1 Hiyoshi, Yokohama 223-8522, Japan.E-mail: einaga@chem.keio.ac.jp

${ }^{b}$ Photocatalysis International Research Center, Tokyo University of Science, 2641 Yamazaki, Noda, Chiba 278-8510, Japan

${ }^{c}$ ACCEL, Japan Science and Technology Agency, 5-3 Yonbancho, Chiyoda 102-8666, Japan practical use of an energy conversion system, water-based solutions are more convenient than organic solvents. Compared with such metal electrodes, BDD electrodes have greater chemical and mechanical stability. As previously reported, formaldehyde can be produced with high yield from $\mathrm{CO}_{2}$ using BDD electrodes and water-based solvents. ${ }^{8}$

Recently, the effect of the size of the $\mathrm{AM}$ cation on the production of $\mathrm{CO}, \mathrm{C}_{2} \mathrm{H}_{4}$ and $\mathrm{C}_{2} \mathrm{H}_{5} \mathrm{OH}$ using $\mathrm{Ag}$ and $\mathrm{Cu}$ electrodes has been discussed.9

In this paper, we report on a systematic study of the effect of $\mathrm{AM}$ cations on the FE for the production of formic acid using BDD electrodes. We found that the optimum conditions, obtained using $0.075 \mathrm{M} \mathrm{Rb}^{+}$solution neutralized to $\mathrm{pH} 6.2$ with $\mathrm{HCl}$, gave an $\mathrm{FE}$ of $71 \%$.

\section{Experimental}

BDD thin films were grown using microwave plasma assisted chemical vapor deposition (MPCVD). The boron source, $\mathrm{B}\left(\mathrm{OCH}_{3}\right)_{3}$, was dissolved in acetone (the carbon source) with a B/C atomic ratio of $1.0 \mathrm{w} / \mathrm{w}$. BDD was deposited on $\mathrm{Si}(100)$ wafers in an MPCVD chamber at $5 \mathrm{~kW}$ using high-purity hydrogen as a carrier gas.

To confirm the film quality of the BDD, Raman spectroscopy was performed with Ar laser illumination (Acton-SP2500). The Raman spectra show a narrow peak at $1324 \mathrm{~cm}^{-1}$, which is attributed to the zone center phonon of diamond in the BDD together with larger bands observed around $477 \mathrm{~cm}^{-1}$ and 1204 $\mathrm{cm}^{-1}$. The electric resistivity was about $2 \mathrm{~m} \Omega \mathrm{cm}$, as we reported before. ${ }^{10}$

The electrochemical experiments were performed in a twocompartment H-type cell $(100 \mathrm{~mL})$, using a platinum counter 
electrode and $\mathrm{Ag} / \mathrm{AgCl}$ reference electrode. Water was obtained from a Millipore Milli-Q Plus system. All the chemicals used here, except $\mathrm{RbOH}$, were purchased from Wako pure chemicals. $\mathrm{RbOH} \cdot \mathrm{H}_{2} \mathrm{O}$ was purchased from Yoneyama Chemicals.

The BDD electrodes were sonicated in ultrapure water prior to use. The experimental procedure was as follows: first, $\mathrm{N}_{2}$ gas was bubbled into the electrolytes for $30 \mathrm{~min}$ at a rate of $200 \mathrm{sccm}$ to remove oxygen. Then, $\mathrm{CO}_{2}$ gas was bubbled into the electrolytes for $5 \mathrm{~min}$ at a rate of $500 \mathrm{sccm}$. After that, the bottle containing the electrolytes was shaken for $5 \mathrm{~min}$ to obtain a saturated solution of $\mathrm{CO}_{2}$. The $\mathrm{pH}$ of the saturated solution was neutralized to 6.2 with the addition of $\mathrm{HCl} .50 \mathrm{~mL}$ of the saturated solution, to be used as the catholyte, was poured into the cathode part of the electrochemical cell. As for the anolyte, a solution with the same concentration as the catholyte, but without the $\mathrm{pH}$ adjusted, was used. All the electrolysis experiments were performed at a constant current of $-10 \mathrm{~mA}$ for $1 \mathrm{~h}$. The faradaic efficiency was calculated from the mass of the product compared with the amount of charge (36 C) used in the experiments. The $\mathrm{CO}$ and hydrogen were analyzed by gas chromatography with a flame ionization detector (FID) and a thermal conductivity detector (TCD) (GC-2014, Shimadzu Corp.). The formic acid was analysed by high performance liquid chromatography (HPLC) with an electroconductivity detector (Prominence, Shimadzu Corp.). The electrodes were characterized by scanning electron microscopy (JCM-6000, JEOL).

\section{Results and discussion}

\section{Effect of $\mathrm{pH}$ on the faradaic efficiency for the production of formic acid}

Since alkaline solutions strongly absorb $\mathrm{CO}_{2}$, we chose $\mathrm{NaOH}$, $\mathrm{KOH}, \mathrm{RbOH}$ and $\mathrm{CsOH}$ as the supporting electrolytes. For $0.5 \mathrm{M}$ $\mathrm{KOH}$, the $\mathrm{pH}$ stayed at around 9.5 after saturation of the $\mathrm{CO}_{2}$. At $\mathrm{pH}$ 9.5, we confirmed that no formic acid was produced after electrolysis at $10 \mathrm{~mA}$ for $1 \mathrm{~h}$. Upon dissolving $\mathrm{CO}_{2}, \mathrm{CO}_{3}{ }^{2-}$, $\mathrm{HCO}_{3}{ }^{-}$or $\mathrm{H}_{2} \mathrm{CO}_{3}$ is formed in the solution. ${ }^{11}$ At high $\mathrm{pH}, \mathrm{CO}_{3}{ }^{2-}$ is the dominant species formed. By adjusting the $\mathrm{pH}$ to lower values, the presence of $\mathrm{HCO}_{3}{ }^{-}$becomes evident, which is deemed to be the species responsible for the formation of formic acid. Using a $0.05 \mathrm{M} \mathrm{Rb}^{+}$solution, we determined the optimum $\mathrm{pH}$ required to produce formic acid from $\mathrm{CO}_{2}$. After shaking for $5 \mathrm{~min}$, the $\mathrm{pH}$ stays at around 7, with the $\mathrm{CO}_{2}$ concentration above $2020 \mathrm{mg} \mathrm{L}^{-1}$.

The FE was calculated by the following equation.

$$
\mathrm{FE}(\%)=(n \times C \times F) / Q \times 100
$$

here, $n$ is the number of electrons for the formation of products, $C$ is the amount of the products (mol), $F$ is the faradaic constant (C mol${ }^{-1}$ ), $Q$ is the charges consumed for the formation of the products $(C)$. The error of the liquid products was evaluated to $5 \%$ by measuring the same samples repeatedly. Also, the error of gaseous products was estimated to $10 \%$.

Fig. 1 shows the relationship between the $\mathrm{pH}$ of the $\mathrm{CO}_{2}$ saturated $0.05 \mathrm{M} \mathrm{Rb}^{+}$solution neutralized with $\mathrm{HCl}$ and the $\mathrm{FE}$ for the formation of formic acid. The optimum $\mathrm{pH}$ was found to be around 6.2. In the case of the $0.05 \mathrm{M} \mathrm{Rb}^{+}$electrolyte, the maximum $\mathrm{FE}$ was $66 \%$. These results show that $\mathrm{HCO}_{3}{ }^{-}$, produced from the bubbled $\mathrm{CO}_{2}$, plays an important role in forming formic acid on the surface of the BDD electrode. The potential during electrolysis was highly negative, about -2.2 to $-3 \mathrm{~V}$, which is sufficient to form co-adsorption structures comprising alkali-cations and $\mathrm{HCO}_{3}{ }^{-}$on the BDD electrode.

The reaction mechanisms for the formation of formic acid and CO have been reported elsewhere. ${ }^{5,6,9}$ Two electrons are involved in each of these reactions.

The overall reactions for the formation of formic acid and $\mathrm{CO}$ are as follows,

$$
\begin{gathered}
\mathrm{CO}_{2}+2 \mathrm{H}^{+}+2 \mathrm{e}^{-}=\mathrm{HCOOH} \\
\mathrm{CO}_{2}+2 \mathrm{H}^{+}+2 \mathrm{e}^{-}=\mathrm{CO}+\mathrm{H}_{2} \mathrm{O}
\end{gathered}
$$

Both reactions (1) and (2) are related to ${ }^{\circ} \mathrm{CO}_{2}$ radicals adsorbed on the electrode surface. As noted in a previous review, ${ }^{12}$ the weakly adsorbed ${ }^{\circ} \mathrm{CO}_{2}$ radicals form the formic acid. On the other hand, the stably adsorbed ${ }^{\circ} \mathrm{CO}_{2}$ radicals produce gaseous $\mathrm{CO}$.

We have often experienced that the $\mathrm{FE}$ value of $55 \%$ with a newly-grown BDD electrode settled down to $20 \%$ after $c a .30$ batch tests in $0.1 \mathrm{M} \mathrm{K}^{+}$solutions with $\mathrm{pH}$ 6.2. Each batch test consists of an hour electrochemical reduction experiment of $\mathrm{CO}_{2}$. The immersion of BDD electrodes into aqua regia solution overnight often gives good restoration effect. However, the FE for formic acid production eventually degraded down to $20 \%$. Once the FE degraded $20 \%$, the FE never recovered in the case of $0.1 \mathrm{M}$ $\mathrm{K}^{+}$solutions with $\mathrm{pH} 6.2$ even if we applied the electrochemical oxidation of BDD electrodes. On the contrary, in $\mathrm{Rb}^{+}$solution, the FEs easily recovered by the electrochemical methods. The question is why the FEs obtained in $0.1 \mathrm{M} \mathrm{K}^{+}$solution never recover again. There are a couple of possible explanations for this question. First, the oxygen species formed by electrochemical pretreatment consist of several kinds of adsorbates. Namely, atomic oxygen, hydroxyl group or other chemical species are thought to be mixed on BDD surfaces. Among them, some species might hamper the adsorption of alkali-metal cations. So, in $0.1 \mathrm{M} \mathrm{K}^{+}$solution, $\mathrm{K}$ cations would be adsorbed on the oxygen, not on the hydroxyl groups formed on oxidized BDD electrodes. It can be speculated that the population of each oxygen species

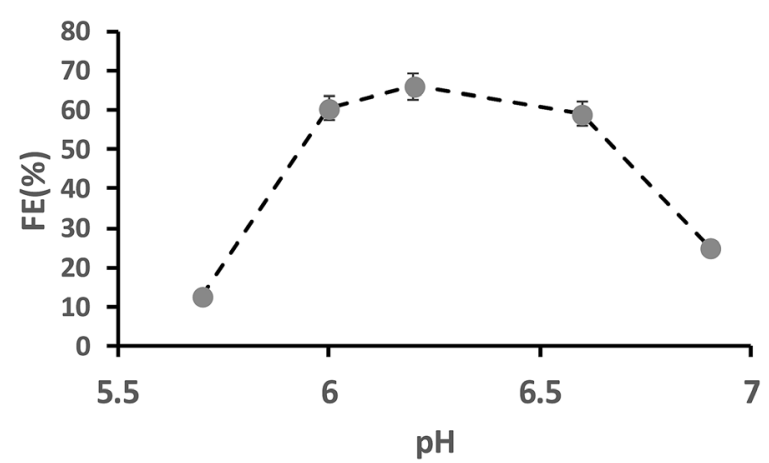

Fig. 1 Effect of $\mathrm{pH}$ on the FE for the formation of formic acid in $\mathrm{a} \mathrm{Rb}^{+}$ solution. 
changes irreversibly in the course of the successive electrochemical reduction process and electrochemical oxidation cycles. That causes the hysteresis of the effect of conversion of $\mathrm{CO}_{2}$ to formic acid using $0.1 \mathrm{M} \mathrm{K}^{+}$solution. Compared with $\mathrm{K}^{+}$, the larger $\mathrm{Rb}$ cations would easily stick to oxidized BDD electrode surfaces, which provide the reversible results. Another possible explanation of the irreversible effect of conversion of $\mathrm{CO}_{2}$ in $\mathrm{K}^{+}$solution would be the adsorbates-induced surface restructuring on BDD electrode surfaces. In the case of $\mathrm{Au}(110)$ electrode surface, Weaver and Gao have reported that the reconstructed structures of this surface are different depending on the cation species between $\mathrm{K}$ and $\mathrm{Cs}$ in aqueous solutions. ${ }^{13}$ Although there have been no papers reported on single crystal BDD surfaces in solutions, there might be the irreversible structural changes occurred in $\mathrm{K}^{+}$solution.

\section{Effect of AM cations on the faradaic efficiency for the production of formic acid}

We fixed the $\mathrm{pH}$ to 6.2 for all the electrolytes and chose $\mathrm{NaOH}$, $\mathrm{KOH}, \mathrm{RbOH}$ and $\mathrm{CsOH}$ to examine the effect of AM cations on the formation of formic acid. For all the electrolytes, the FE changes depending on the concentration of the electrolyte, as shown in Fig. 2(a). The FE reaches $71 \%$ for a $0.075 \mathrm{M} \mathrm{Rb}^{+}$ solution. For the $\mathrm{Rb}^{+}$solution, the FE stays above $50 \%$ over a wide concentration range from $0.02 \mathrm{M}$ to $0.2 \mathrm{M}$. Also, for the $\mathrm{Rb}^{+}$solution, the FE for the formation of CO is very low, being less than $0.1 \%$, as shown in Fig. 2(b).

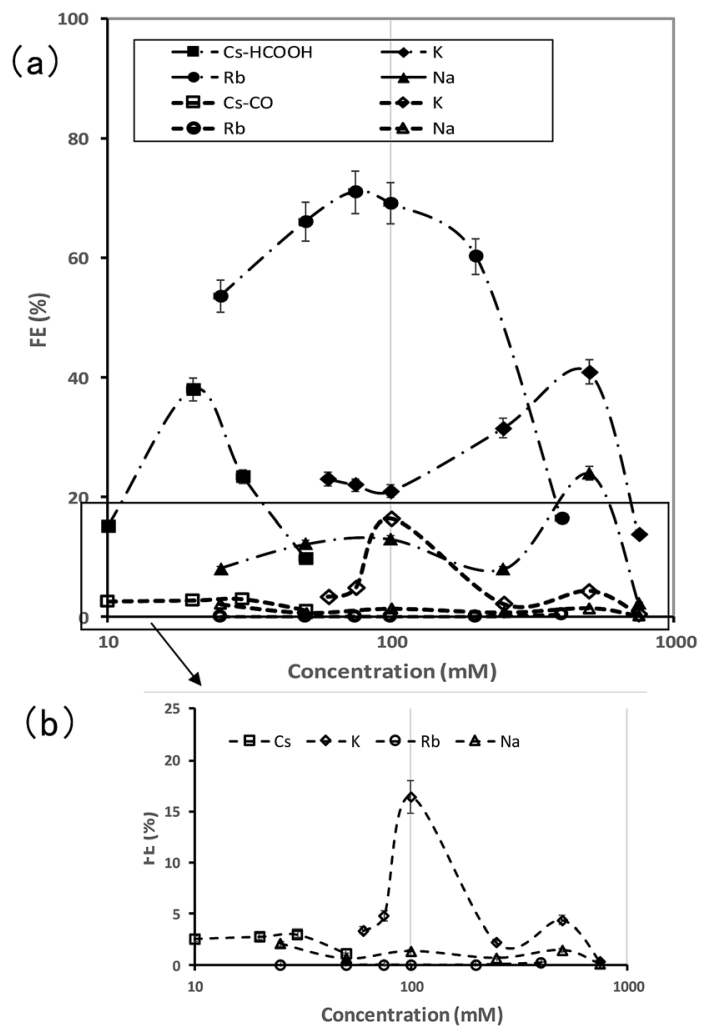

Fig. 2 Dependency of the FE for the production of formic acid (a) and $\mathrm{CO}$ (b) on the concentration of the solutions. The dotted lines in the figures are guides for the eye.
For the $\mathrm{Cs}^{+}$solution, the peak of the FE curve for the production of formic acid appears at $0.02 \mathrm{M}$. The maximum FE is at $38 \%$ at. Despite $\mathrm{Cs}^{+}$being the largest size among the AM cations described here, the peak FE is much lower than that obtained with $\mathrm{Rb}^{+}$. The reason for this is still unclear, unfortunately.

In contrast to these two solutions, the $\mathrm{FE}$ peaks for the $\mathrm{K}^{+}$ and $\mathrm{Na}^{+}$solutions stay at around $0.5 \mathrm{M}$. For the $\mathrm{K}^{+}$solution, the maximum FE is $41 \%$. The FE of $24 \%$ in case of the $\mathrm{Na}^{+}$solution is the lowest value.

We measured the electrical conductivities of $\mathrm{Cs}^{+}$and $\mathrm{Rb}^{+}$ solutions, and found they were twice those of $\mathrm{K}^{+}$and $\mathrm{Na}^{+}$ solutions. One of the reasons why the positions of the peaks move toward lower values for $\mathrm{CsOH}$ and $\mathrm{RbOH}$ is the difference in electrical conductivities.

Fig. 3 shows cyclic voltammograms recorded for a BDD electrode in $\mathrm{CO}_{2}$ saturated $\mathrm{Na}^{+}, \mathrm{K}^{+}, \mathrm{Rb}^{+}$and $\mathrm{Cs}^{+}$solutions with $\mathrm{pH}$ 6.2. The hydrogen evolution behaviors in the $\mathrm{Cs}^{+}$and $\mathrm{K}^{+}$ solutions were quite similar. Of the four electrolytes, hydrogen evolves most easily in $\mathrm{Na}^{+}$solution. In $\mathrm{Rb}^{+}$solution, however, we can confirm that the hydrogen evolution was suppressed. These phenomena partly explain why the maximum $\mathrm{FE}$ for the production of formic acid was observed in the $\mathrm{Rb}^{+}$solution.

The interactions between $\mathrm{Na}^{+}, \mathrm{K}^{+}, \mathrm{Rb}^{+}$and $\mathrm{Cs}^{+}$and water molecules have been calculated using ab initio molecular orbital calculations. ${ }^{\mathbf{1 4}}$ The interaction energies between these four AM cations and water molecules are $c a .-32,-22,-20$, and -16 kcal $\mathrm{mol}^{-1}$, respectively. So, the stronger the interaction between the AM cation and water is, the lower the FE for the production of formic acid. In the potential range where the electro-reduction of $\mathrm{CO}_{2}$ proceeds, the AM cations are thought to be adsorbed on the BDD surface. In the case of the $\mathrm{Na}^{+}$ solution, we consider that the strong interaction between $\mathrm{Na}^{+}$ and the water molecules hampers the adsorption of $\mathrm{Na}^{+}$cations on the BDD surface. As for the $\mathrm{K}^{+}$solution, interestingly, $50 \%$ of the product formed with a $0.1 \mathrm{M}$ solution was $\mathrm{CO}$. On increasing the concentration of the $\mathrm{K}^{+}$solution, more formic acid was produced and was the main product with a $0.5 \mathrm{M}$ solution. When $\mathrm{CO}_{2}$ anion radicals are stably adsorbed on the surface of

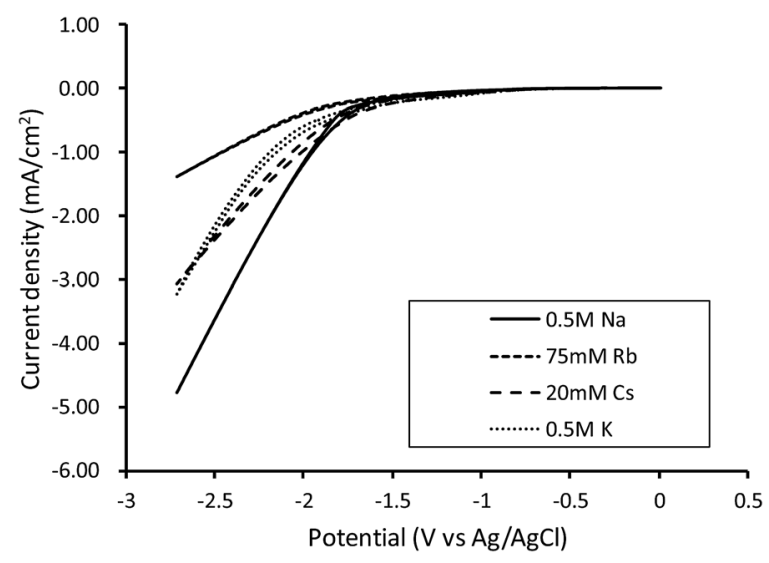

Fig. 3 Cyclic voltammograms for BDD electrodes in $\mathrm{Na}^{+}, \mathrm{K}^{+}, \mathrm{Rb}^{+}$and $\mathrm{Cs}^{+}$solutions with $\mathrm{pH}$ 6.2. The scan rate was $100 \mathrm{mV} \mathrm{s}^{-1}$. 


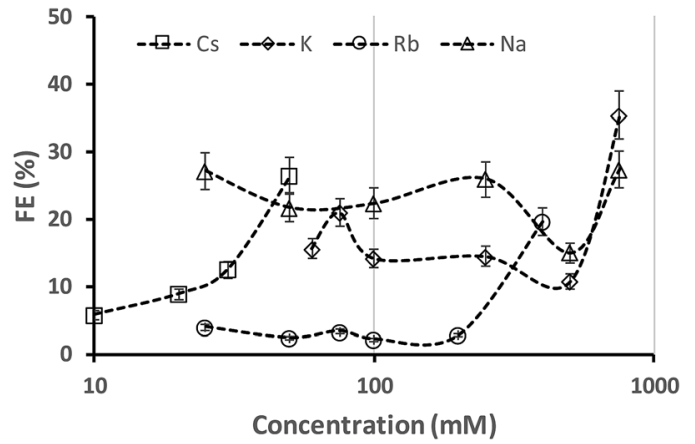

Fig. 4 Dependency of FE for the generation of $\mathrm{H}_{2}$ on the concentration of the solutions. The dotted lines in the figure are guides for the eye.

$\mathrm{BDD}$, the production of $\mathrm{CO}$ becomes more dominant as previously reported. ${ }^{9}$ From this result, we can speculate that the composition of the adsorbates, which includes $\mathrm{K}^{+}, \mathrm{HCO}_{3}{ }^{-}$and water molecules, changes depending on the concentration of $\mathrm{K}^{+}$. Other than with $\mathrm{K}^{+}$solution, such changes in the products with the concentration of AM cations were not observed, and the $\mathrm{FE}$ for $\mathrm{CO}$ is independent of the concentration of cations. Fig. 4 shows the $\mathrm{FE}$ curve for $\mathrm{H}_{2}$ as a byproduct of the reduction of $\mathrm{CO}_{2}$. Although in our experiments the sum of all the products and byproducts, inexplicably, does not reach $100 \%$, we are able, nevertheless, to discuss the behavior of the formation of $\mathrm{H}_{2}$ on BDD surfaces. The dependency on concentration seems to be similar for all the electrolytes. The $\mathrm{FE}$ of $\mathrm{H}_{2}$ increases with the increasing concentration of the AM solution. Note that the $\mathrm{FE}$ for the production of $\mathrm{H}_{2}$ in $\mathrm{Rb}^{+}$solution remains at a very low value of less than $c a .5 \%$ over a wide concentration range from $0.02 \mathrm{M}$ to $0.2 \mathrm{M}$. $\mathrm{Rb}^{+}$cations hydrated with water molecules are thought to be strongly adsorbed and to completely cover the BDD surface. As a result, atomic hydrogen arises from the decomposition of water molecules that are unable to occupy any surface sites. Our results encourage us to carry out further studies of the atomic-level structure of electrochemical doublelayers formed on BDD electrodes.

Singh et al. ${ }^{9}$ studied the effect of the size of the AM cation on the $\mathrm{FE}$ for the production of $\mathrm{CO}$ with $\mathrm{Ag}$ and $\mathrm{Cu}$ electrodes. As the size of the cation is increased, the evolution of hydrogen decreases and the FE for the production of $\mathrm{CO}$ increases. They considered that the $\mathrm{pH}$ buffering effect near the electrode enhances the FE for the production of $\mathrm{CO}$. However, our results for the FE for the production of formic acid simply don't concur with this premise. $\mathrm{Rb}^{+}$ions hydrated with water molecules are the best cations for enhancing the production of formic acid.

Under ultra-high vacuum conditions, the adsorption behaviors of $\mathrm{K}$ and $\mathrm{Cs}$ on both hydrogen and oxygen terminated $\mathrm{C}(100)$ surfaces have been reported. ${ }^{15,16}$ However, no data were obtained for the adsorption of Rb on C(100). DFT calculations were done with AMs on both hydrogen and oxygen terminated $\mathrm{C}(100)$ surfaces in which no extraordinary changes in work function or band structure were observed for $\mathrm{Rb}$ adsorbed surfaces. ${ }^{17-19}$ X-ray standing wave spectroscopy studies have shown that a cation like $\mathrm{Rb}^{+}$is able to form inner sphere

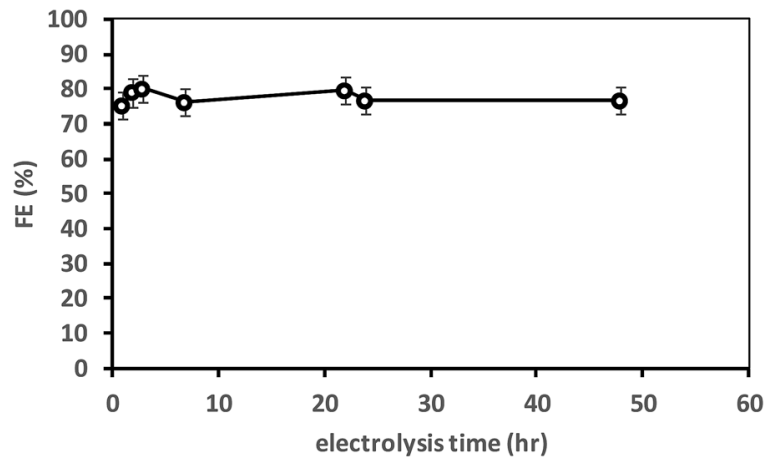

Fig. 5 Variation in the FE with time for continuous electrochemical reduction at $2 \mathrm{~mA} \mathrm{~cm}^{-2}$ with a $0.1 \%$ BDD electrode.

complexes at the surface of $\mathrm{TiO}_{2}(110)$ when the surface is strongly negatively charged. ${ }^{20,21}$ In such a case, the cation is partially dehydrated and directly coordinated to the surface groups.

Therefore, the reasons for the extraordinary effect of $\mathrm{Rb}$ on the production of formic acid can't be clarified but it might be related to the structure of the electric double layer formed on the BDD electrode.

Continuous electrochemical reduction at a high electrode potential often causes damage to electrode materials such as HOPG (highly oriented pyrolytic graphite) and glassy carbon..$^{22}$

In contrast, BDD is highly durable. We confirmed that continuous operation at $2 \mathrm{~mA} \mathrm{~cm}{ }^{-2}$ for $48 \mathrm{~h}$ gave no change in the $\mathrm{FE}$ for the production of formic acid, as shown in Fig. 5. In this experiment, $0.1 \%$ BDD was used. $0.075 \mathrm{M} \mathrm{Rb}^{+}$solution and $0.5 \mathrm{M} \mathrm{KOH}$ were chosen as the anolyte and catholyte, respectively.

\section{Higher productivity for formic acid at higher current densities}

Not only the FE but also the productivity of the products is important in terms of engineering. Although the FE stays high, the amount of product is sometimes very small. ${ }^{23}$ In some cases, only 2-10 $\mathrm{mg} \mathrm{L}^{-1}$ of formic acid could be obtained despite the high FE. Although the current density in the aforementioned experiments was fixed at $2 \mathrm{~mA} \mathrm{~cm}{ }^{-2}$, we applied higher current densities up to $20 \mathrm{~mA} \mathrm{~cm}{ }^{-2}$ as the next challenging target, which determines the reaction speed. This allowed us to determine the size and cost of electrochemical reduction plants.

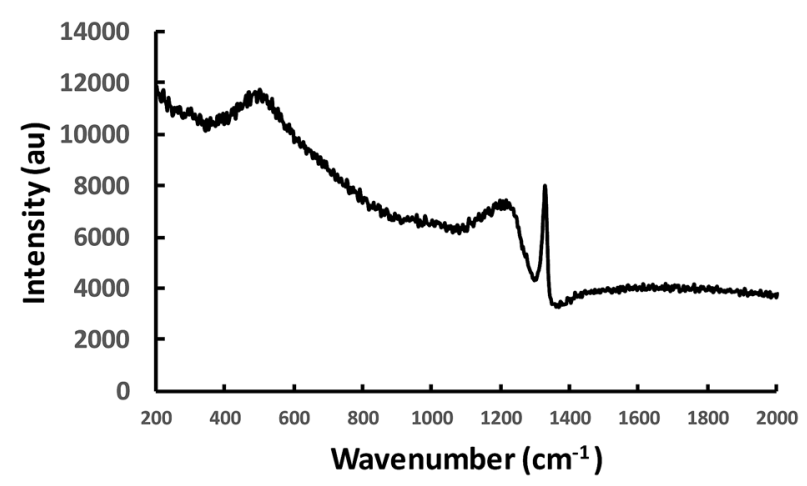

Fig. 6 Raman spectrum of 1\% BDD electrode. 


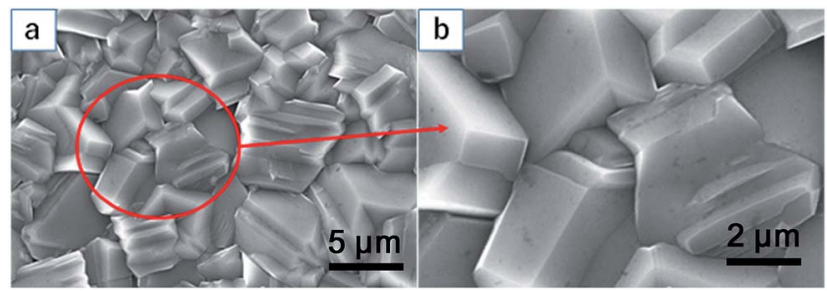

Fig. 7 SEM images of 1\% BDD electrode after experiments. Largerscale image (a) and magnified image (b).

With $0.5-2 \mathrm{M} \mathrm{KOH}$ as the anolyte solution, the FE for the production of formic acid in $0.075 \mathrm{M} \mathrm{Rb}^{+}$catholyte was extended to $86 \%$. We can confirm that more than $1 \mathrm{~g} \mathrm{~L}^{-1}$ of formic acid can be generated in an hour.

\section{Characterization of BDD electrodes}

Fig. 6 shows a Raman spectrum obtained on the 1\% BDD electrode before doing experiments. The characteristic $\mathrm{sp}^{3}$ structure at the band of $1324 \mathrm{~cm}^{-1}$ was confirmed. Then, after the $\mathrm{CO}_{2}$ reduction, the spectrum did not change (data not shown).

Fig. 7 shows the SEM images recorded on the 1\% BDD electrode after 30 hour operations. Clearly evident are the facets of the diamond grains and no etching was received on the magnified image (Fig. 7(b)).

\section{Comparison of the present data with the literatures}

There were many reports published on the conversion of $\mathrm{CO}_{2}$ to formic acid by metal electrodes previously. Hori et al. ${ }^{24}$ reported the formation of formic acid on $\mathrm{Pb}, \mathrm{Hg}, \mathrm{In}, \mathrm{Sn}, \mathrm{Cd}$, $\mathrm{Tl}$ electrodes. The FE of those electrodes stay high above 78.4-99.5\%. Since such metal electrodes have a high environmental load, the usage of them is not recommended. Also, stability of those electrodes seems to be problematic. Recent paper reported the FEs with Sn electrodes. ${ }^{25}$ At ambient condition, the $\mathrm{FE}$ value of $79.5 \%$ was obtained using H-type cell. At high pressure condition the FE reaches $99.2 \%$ at maximum. The electrolytes used were $0.05 \mathrm{M}$ $0.5 \mathrm{M} \mathrm{KHCO}_{3}$ solutions. Therefore, it is the first time to report the extraordinary effect of $\mathrm{Rb}^{+}$on the formation of formic acid by BDD electrodes.

\section{Conclusions}

The electrochemical reduction of $\mathrm{CO}_{2}$ using $\mathrm{BDD}$ electrodes was carried out. We determined the behavior of the $\mathrm{FE}$ for the formation of formic acid in alkaline solutions with different AM cations. The formation of formic acid was confirmed with four alkali-metal solutions. The highest FE of $71 \%$ was observed for a $0.075 \mathrm{M} \mathrm{Rb}^{+}$solution neutralized to $\mathrm{pH} 6.2$ with the addition $\mathrm{HCl}$. The lowest FE was obtained for $\mathrm{Na}^{+}$solution, which has the smallest cation. The dependency of FE on the different kinds of alkali-metal cations has been explained by the interaction between the alkali-metal cations and water molecules. We confirmed that more formic acid is produced at higher current densities.

\section{Notes and references}

1 A. Goeppert, M. Czaun, J.-P. Jones, G. K. Surya Prakash and G. A. Olah, Chem. Soc. Rev., 2014, 43, 7995.

2 T. Saeki, K. Hashimoto, N. Kimura, K. Omata and A. Fujishima, J. Electroanal. Chem., 1996, 404, 302.

3 T. Inoue, A. Fujishima, S. Konishi and K. Honda, Nature, 1979, 277, 638.

4 Y. Chen, C. W. Li and M. W. Kana, J. Am. Chem. Soc., 2012, 134, 19969.

5 J. Wu, F. G. Risalvato, F.-S. Ke, P. J. Pellechia and X.-D. Zhou, J. Electrochem. Soc., 2012, 159, F353.

$6 \mathrm{~J}$. Wu, B. Harris, P. P. Sharma and X.-D. Zhou, ECS Trans., 2013, 58, 71.

7 S. Kaneko, R. Iwao, K. Iiba, K. Ohta and T. Mizuno, Energy, 1998, 23, 1107.

8 K. Nakata, T. Ozaki, C. Terashima, A. Fujishima and Y. Einaga, Angew. Chem., Int. Ed., 2014, 53, 871.

9 M. R. Singh, Y. Kwon, Y. Lum, J. W. Ager III and A. T. Bell, J. Am. Chem. Soc., 2016, 138, 13006.

10 T. Watanabe, Y. Honda, K. Kanda and Y. Einaga, Phys. Status Solidi A, 2014, 211, 2709.

11 H. Zhong, K. Hujii, Y. Nakano and F. Jin, J. Phys. Chem. C, 2015, 119, 55.

12 R. P. S. Chaplin and A. A. Wragg, J. Appl. Electrochem., 2003, 33, 1107.

13 X. Gao and M. J. Weaver, Surf. Sci., 1994, 313, L775.

14 E. D. Glendening and D. Feller, J. Phys. Chem., 1995, 99, 3060.

15 S. Petrick and C. Benndorf, Diamond Relat. Mater., 2001, 10, 519.

16 L. Diederich, O. M. Kuttel, P. Aebi, E. Maillard-Schaller, R. Fasel and L. Schlapbach, Diamond Relat. Mater., 1998, 7, 612.

17 K. M. O'Donnell, T. L. Martin and N. L. Allan, Chem. Mater., 2015, 27, 1306.

18 J. L. Nie, H. Y. Xiao, X. T. Zu and F. Gao, Chem. Phys., 2006, 326, 308.

19 J. L. Nie, H. Y. Xiao, X. T. Zu and F. Gao, Phys. B, 2006, 383, 219.

20 P. Fenter, L. Cheng, S. Rihs, M. Machesky, M. J. Bedzyk and N. C. Sturchio, J. Colloid Interface Sci., 2000, 225, 154.

21 Z. Zhang, P. Fenter, L. Cheng, N. C. Sturchio, M. J. Bedzyk, M. Predota, A. Bandura, J. D. Kubicki, S. N. Lvov, P. T. Cummings, A. A. Chialvo, M. K. Ridley, P. Benezeth, L. Anovitz, D. A. Palmer, M. Machesky and D. J. Wesolowski, Langmuir, 2004, 20, 4954.

22 G. M. Swain, J. Electrochem. Soc., 1994, 141, 3382.

23 H.-Y. Kim, I. Choi, S. H. Ahn, S. J. Hwang, S. J. Yoo, J. Han, J. Kim, H. Park, J. H. Jang and S.-K. Kim, Int. J. Hydrogen Energy, 2014, 39, 16506.

24 Y. Hori, H. Wakabe, T. Tsukamoto and O. Koga, Electrochim. Acta, 1994, 39, 1833.

25 J. Wu and X.-D. Zhou, Chin. J. Catal., 2016, 37, 999. 